\title{
Safety and Efficacy of Repurposed Siddha Medicines in Mild, Moderate, and Severe COVID-19 Patients Admitted To a Government Tertiary Hospital Near Chennai, Tamil Nadu- An Open-Labeled, Randomized, Controlled Trial.
}

Christian G J ( $\nabla$ christianvijila@gmail.com )

NATIONAL INSTITUTE OF SIDDHA https://orcid.org/0000-0002-7325-340X

Meenakumari Ramasamy

NIS: National Institute of Siddha

Shanthimalar Ramalingam

Government Chengalapttu medical college and Hospital

Sankar Ganesan

Ezhil Siddha Hospital

Ravichandran Vadugam Muthusamy

SKM Siddha Ayurveda Company Private Limited

Elansekaran Selladurai

NIS: National Institute of Siddha

Ramamurthy Murugan

NIS: National Institute of Siddha

Srinivasan Venkatachalam

NIS: National Institute of Siddha

Rajalakshmi Elumalai

ICMR

Boopathi Kangusamy

ICMR

Vennila Kesavan

NIS: National Institute of Siddha

Nijavizhi Mohanasundaram

NIS: National Institute of Siddha

Shakthi Paargavi Ambalavanan

National Institute of Siddha

Aruldevi S

NIS: National Institute of Siddha

Priyanka Sekaran

NATIONAL INSTITUTE OF SIDDHA

Gajalakshmi Govindasamy

National Institute of Siddha

Research Article 
Keywords: COVID-19, ITT analyses, Siddha regimen, Hazard ratio

Posted Date: December 22nd, 2021

DOI: https://doi.org/10.21203/rs.3.rs-999914/v1

License: (c) (i) This work is licensed under a Creative Commons Attribution 4.0 International License. Read Full License 


\section{Abstract}

\section{Background}

COVID-19 resulted in loss of human lives owing to respiratory failure caused by dysregulated immune system. Though many treatments are evaluated, the most appropriate is yet to be established. We hypothesized accelerated recovery and reduced mortality in mild, moderate and severe COVID-19 with Siddha regimen consisting of natural products.

\section{Methods}

In a randomized, controlled open-label trial conducted on 200 hospitalized COVID-19 patients, they were allocated equally to be treated with add-on Siddha regimen with Standard care or only standard care.

The primary and secondary end points were accelerated recovery ( $\leq 7$ days) and mortality comparison between the groups respectively. Patients were followed through 90 days.

\section{Results}

In this study the accelerated recovery was $59.0 \%$ and $27.0 \%$ in treatment and control group (ITT analyses) $(p<0.001)$ respectively and Odds for it were four times higher in the treatment group (OR: 3.9; 95\% $\mathrm{Cl}: 1.9,8.0)$. The estimated median time for recovery in the treatment group was 7 days $(95 \% \mathrm{Cl}: 6.0,8.0 ; \mathrm{p}=0.003)$ and 10 days $(95 \% \mathrm{Cl}: 8.7,11.3)$ in control. Hazard ratio for death in control was 2.3 times that of treatment group. No adverse reactions or alarming laboratory values were observed in response to intervention. In severe treatment group $(n=80)$, mortality was $15.0 \%$ and $39.5 \%$ in control $(n=81)$. The COVID stage progression was $65 \%$ less in treatment group.

\section{Conclusion}

Siddha regimen demonstrated that they can synergistically improve oxygenation status, enhance the recovery rate and reduce the mortality better as compared to only Standard of Care.

\section{Introduction}

The pandemic of COVID-19 disease has devastated millions of humans with a loss to life, family, peace and prosperity affecting physical and mental wellbeing. More than 228 million confirmed cases of COVID-19 including 4.69 million deaths have been reported globally till September 2021 by World Health Organization (WHO) since it was first identified in China. India has experienced a devastating second wave of COVID-19 pandemic since April 2021 accounting for nearly $50 \%$ of the global active COVID-19 cases [1]. Tamil Nadu was among the top five Indian states with 2 million confirmed cases at the end of May 2021[2].

SARS-CoV-2 infection is reported with a range of clinical manifestations, from no symptoms to critical illness. In general, SARS-CoV-2 infection can be categorized into asymptomatic, mild, moderate, severe and critical illness. However, the criteria for each category may overlap or vary and a patient's clinical status may change over time [3]. Most people with COVID-19 experience mild and moderate symptoms and approximately 10-15\% of cases progress to severe disease and about $5 \%$ become critically ill [4]. The most common symptoms being fever, cough, sore throat, malaise, headache, muscle pain, nausea, vomiting, diarrhea, loss of taste and smell [3] [5]. Patients with only mild disease present with low fever and slight asthenia, without pneumonia and breathlessness. The prognosis of most mild patients is good, with the mortality rate ranging from 0 to $14.6 \%$ [6] [7]. Mortality of patients admitted in intensive care unit is $21.6 \%$ in United States [8]. The prognosis of the elderly and those with underlying chronic conditions is poor [9]. Old age and certain comorbidities including obesity, Diabetes mellitus, chronic pulmonary diseases and chronic kidney disease have been found to be associated with high risk for hospitalization or death [10]. 
The treatment protocol guidelines of Standard of Care (SOC) was released by the Ministry of Health and Family Welfare, Government of India (GOI) which includes the general symptomatic management and intensive respiratory care to the critical COVID-19 patients [11]. During the early pandemic, the Ministry of AYUSH, (Ayurveda, Yoga and Naturopathy, Unani, Siddha and Homeopathy), Govt. of India (GOI) and the Govt. of Tamil Nadu, India has released advisory and guidelines for the prophylaxis, management and convalescence of COVID-19 using AYUSH medicines including Siddha in India $[12,13]$.

One of the AYUSH systems, the Siddha system of medicine describes the clinical features and various stages of SARSCoV-2 infection comparable under the headings Kabasuram (lya suram), Kabavatha suram and Sannipatha suram in Siddha system of medicine. It can be considered as the prototype description of any fever with predominant pulmonary inflammations as per the Siddha literature [14]. According to Siddha pathophysiology, Kaba suram is due to elevation of lyam, which is one of the three humors of the human body. Vitiated lyam, Vali and Azhal humors all at the same time lead to the state of Sanni which is a state of apoplexy akin to the severe stage of COVID-19 [15].

In countries like India, the overwhelming numbers of COVID-19 incidence put an enormous strain on the framework of health system beyond its scope to manage with respect to the number of hospital beds, workforce and facilities required to treat moderate and severe cases. Preventing mortality and promoting accelerated recovery from SARS-CoV-2 infection are extremely essential in order to manage the pandemic effectively with the available resources. In view of the rapid transmission of infection and a lack of effective therapies, research on the complementary treatment of COVID-19 is a dire necessity. Though the Siddha formulations have been in use since time immemorial for treating various ailments, it requires systematic studies and rigorous clinical research to demonstrate the safety and efficacy for repurposing of Siddha drugs in COVID-19 management.

Recently, a molecular docking study of a Siddha poly herbal formulation Kabasura Kudineer (KSK) identified about 15 natural compounds suggestive of inhibiting SARS-CoV-2 as they gave a better energy score compared to synthetic drugs [16]. An in-silico computational study wherein out of 37 of the screened compounds of the same herbal formulation, 9 showed high binding affinity against SARS-CoV-2 spike protein [17]. A recently published review article highlighted the usefulness of Siddha herbs for the effective management of respiratory ailments and as immune boosters [18]. Kabasura kudineer is one such poly-herbal formulation that has been studied for its anti-viral properties through in-silico computational screening against SARS-CoV-2 spike proteins [17]. A single case study on mild COVID-19 reported that administration of the Siddha drug Thalisathy churnam (part of the regimen in our study) worked well for the patient to recover from COVID 19 clinical symptoms within a week [19]. Nochi Kudineer and Adathodai Kudineer, two of the selected polyherbal Siddha formulations used in our study for moderate and severe COVID-19 disease, showed anti-viral property as reported in an in-vitro study [20]. Also, Adathodai Kudineer has been shown to have anti SARS-CoV-2 activity through computational study of compounds isolated by Gas chromatography-mass spectrometry (GC-MS) method. They were found to have high energy affinity against the SARS-CoV-2 spike protein (PDB ID 6LU7) and its complex with Angiotensin converting enzyme 2 (ACE 2) receptor of human cells (PDB ID 6LZG) [21]. Further, an open clinical evaluation of the additional therapeutic effect of selected Siddha formulations among the asymptomatic, mild and moderate category of COVID-19 patients has demonstrated the accelerated recovery as compared to only Standard of Care management [22]. No clinical trial has been reported so far using AYUSH interventions on severe category of SARSCoV-2 infection to the best of our knowledge. In this context, we conducted a randomized controlled trial to determine the safety and efficacy of selected Siddha formulations as co-intervention with Standard of Care among the mild, moderate and severe COVID-19 patients in terms of determining the accelerated recovery and prevention of death compared with that of only Standard of Care as control group.

\section{Methods}




\subsection{Study design}

A prospective, single center, open-label randomized controlled trial was conducted. The trial was conducted jointly by National Institute of Siddha, Chennai and Government Chengalpattu Medical College Hospital, Chengalpattu district, Tamil Nadu, India between July and December 2020.

\subsection{Patients}

Eligible patients were men and non-pregnant, non-lactating women with COVID-19, aged 18 to 85 years confirmed by RTPCR positive assay for SARS-CoV-2 in nasopharyngeal and oropharyngeal swab specimens and / or pneumonia confirmed by pulmonary imaging. Exclusion criteria (before randomization) includes inability to have oral feeding (that precludes oral administration of Siddha drugs); diabetic ketosis, diabetic nephropathy, septicemia / Multi Organ Dysfunction Syndrome (MODS); known severe renal impairment (estimated glomerular filtration rate $<30 \mathrm{~mL} / \mathrm{min} \mathrm{per}$ $1.73 \mathrm{~m}^{2}$ ) or receipt of continuous renal replacement therapy, alanine aminotransferase (ALT) / aspartate aminotransferase (AST) more than 5 times the normal upper limit and total bilirubin 3 times higher than the normal upper limit; participating in another therapeutic clinical trial for COVID-19 before or at the same period; severe heart diseases, severe COVID-19 with more pronounced ARDS $\left(\mathrm{PaO}_{2} / \mathrm{FiO}_{2}<200 \mathrm{~mm} / \mathrm{Hg}\right)$ at enrollment, critical COVID-19 patients with life expectancy $<48$ hours, and who had severe underlying diseases that affects survival, including blood diseases, dyscrasia, active bleeding and severe malnutrition. Withdrawal criteria (excluded after randomization) includes patients who did not tolerate the trial drugs and develop adverse reactions during the drug trial, developing ARDS within 48 hours of enrollment, also any inter-current illness which would warrant other extended drug treatment were to be withdrawn. Patients wanting to withdraw from the study were also allowed to do so.

\subsection{Intervention:}

Details of Siddha regimen and Standard of Care is given in the Table 1 
Table 1

Details of drug intervention

Siddha interventions

Standard of Care

Asymptomatic / Mild COVID-19

Moderate / Severe COVID-

19

Kabasura Kudineer [50] Nilavembu

kudineer [51] - 60ml tid in

symptomatics \& bid in

asymptomatics $(5 \mathrm{~g}$ each of Kudineer

powder made into $60 \mathrm{ml}$ decoction as

per classic literature)

Amukkura churnam [29] 2g;

Thalisathi churnam [52] (2g) - 4g tid with honey or milk

Adathodai Manappagu [53] 20ml bid with water

Karuppu Vishnu chakram [54] 2 pills bd with honey

Nellikkai Leghyam $5 \mathrm{~g}$ bid
Adathodai Kudineer [55]; Nochi Kudineer [56] - 60ml tid $(5 \mathrm{~g}$ each of Kudineer powder made into $60 \mathrm{ml}$ decoction as per classic literature)

Amukkura churnam[29] 2g; Thalisathi churnam [57] $(2 \mathrm{~g})-4 \mathrm{~g}$ tid with honey or milk

Maldevi (Thaalaga) chenduram $100 \mathrm{mg}$ bid with honey

Pavala parpam [58]100mg bd with honey

Thippili rasayanam [59] 5g bid
Tab. Paracetamol, Tab. Zinc, Tab. Vitamin C, Tab. Azithromycin, Tab.

Hydroxychloroquinone, Inj. Dexamethasone, Inj. Ceftriaxone, Inj. Remdesivir, Inj. Methylprednisolone, Inj. Enoxaparin, Inj.Tocilizumab, Cap. Doxycycline, Tab. Deriphyllin, Tab. N-acetylcysteine and Tab.

Pirfenidone

- The above drugs were administered as per the CLINICAL MANAGEMENT PROTOCOL: COVID-19

Published by Govt. of India Ministry of Health and Family Welfare Directorate General of Health Services (EMR Division) Version 3 (2020)

Herbal tea was administered to all treatment group patients $100 \mathrm{ml}$

twice a day.

Ingredients: Azadiracta indica (leaves), Curcuma longa (rhizome), Ocimum sanctum (leaves), Gyzyrrhiza glabra (root), Syzygium aromaticum (fruit), Terminalia chebula (rind), Alpinia galanga (rhizome), Piper cubeba (fruit), Zingiber officinale (rhizome), Coriandrum sativum (seed) and Palm Jaggery- decoction made out of $10 \mathrm{~g}$ with $200 \mathrm{ml}$ water, boiled down to $100 \mathrm{ml}$, twice a day palm jaggery may be added if not a diabetic.

The treatment group received selected Siddha formulations along with Standard of Care and the control group received only Standard of Care. The trial drugs were procured from Good Manufacturing Practices (GMP) certified pharmaceutical companies under the scrutiny of the State licensing authority of Indian Medicine (SLA-IM) which manufacture and control the quality of drugs in compliance with the Drugs and Cosmetic Act 1940 and Rules 1945[25, 26].

\subsection{Objectives:}

Our primary objective was to determine the proportion of patients who had accelerated recovery treated with selected Siddha drugs along with Standard of Care management and compared with that of patients taken only Standard of Care. The other objectives were to assess for the reduction in all-cause mortality, respiratory and other symptoms due to COVID-19 and prevention of COVID-19 stage progression and compared between the groups.

\subsection{Patient recruitment, Data collection method and outcome measurements:}

Mild, moderate and severe COVID-19 patients were screened using selection criteria and enrolled as study participants after obtaining informed consent. The COVID-19 patients recruited were categorized as mild, moderate and severe as per the Clinical Management Protocol guidelines for COVID-19, issued by the Ministry of Health and Family Welfare, Govt. of India [11]. Those patients who were admitted to the COVID-19 ward within 48 hours of testing positive in mild cases were screened and enrolled. In moderate and severe cases, the time taken from RT PCR testing to admission and enrollment at 
ICU ranged from 5 - 12 days. All the patients were enrolled within 24 hours of admission. As the study was conducted in a tertiary care hospital, selection comprised of severe COVID-19 cases predominantly $(n=161)$. Qualified and trained Siddha Post graduate scholars and consultant physicians were involved in the participant recruitment and data collections were done under the supervision of the study investigators.

The medicines were weighed using high precision electronic balances and packed as single dose in sterile disposable sachets and the decoctions were prepared under aseptic precautions by trained pharmacists as per classical literature. The endpoint assessment methods were adopted from the minimum common outcome measure set developed by the working group of WHO-led international collaborative response team to the outbreak of COVID -19. The outcome measures used in this study were resolution / progression by WHO clinical progression scale, viral burden, mortality, symptoms, co-infection, co-morbidities, biomarkers and post COVID functional parameters. Recovery or resolution is defined with the negative test for RT-PCR, remission of COVID-19 symptoms and the SpO2 (in moderate and severe cases) becoming $\geq 94 \%$ based on WHO clinical progression scale [27]. The discharge policy of Ministry of Health and Family Welfare, Government of India about mild COVID-19 patients was 14 days [28]. 50\% (7 days) of this time period was arbitrarily considered as cut off point for 'accelerated' recovery for mild, moderate and even for severe COVID-19 patients in this study and recovery achieved up to 7 days from enrollment was considered as accelerated recovery in this study. Disease days were calculated from the date of onset of the first symptom (before admission) to date of recovery and the hospital days defined from the date of admission to date of discharge.

\subsection{Sample size:}

The sample size was estimated for a moderate effect size of $0.3,80 \%$ power and level of significance $5 \%$. The sample size was estimated to be 176 and considering a drop out of 10\%, we had to recruit 200 patients.

\subsection{Randomization:}

After the screening through inclusion and exclusion criteria, the study participants were equally allocated in either treatment group or the control group by computer-generated random numbers.

\subsection{Allocation concealment and Implementation:}

Allocation details were sealed in envelopes to conceal the sequence until the intervention was assigned. Chief statistician generated the allocation sequence, investigators and trained PG scholars enrolled and assigned participants to the treatment and control groups. No blinding was done since the color, texture, flavor and taste of Siddha drugs could not be masked.

\subsection{Follow up:}

Post discharge management in the convalescence period (after the completion of treatment and discharged from hospital care): Nellikkai Legium (5gm twice a day after food) and Amukkura Churnam tablet [29] (2 tablets twice a day after food) were prescribed to the treatment group patients at the time of recovery and advised to take for 20 days to prevent the post COVID-19 symptoms as per the 'Aarokyam'special programme of Government of Tamil Nadu [30]. The study participants were followed up through telephone for 90 days (counted from admission) at 3 time points 30th, 60th and 90th days to check for post COVID-19 symptoms and mortality after discharge. During follow up the patients were enquired and assessed for overall functionality, lingering breathlessness and the quality of life through Post-COVID-19 Functional Status Scale (PCFS), Modified Medical Research Council breathlessness scale (mMRC) and European Quality of Life Five Dimension - Five Levels (EQ5D5L) scales respectively [31, 32, 33, 34, 35, 36, 27].

\subsection{Data management and Statistical analysis:}


The collected data was entered into Microsoft Office Excel on the same day. Data cleaning was done by re-entry method and cross verified for the correctness of the data. Data from all the randomized patients were analyzed (intention-to-treat analysis). Descriptive statistics were presented as mean with standard deviation and median with quartiles, and proportions with percentage according to type of data. Chi-Square test was applied to find the association between groups. Binary logistic regression was employed to identify the odds of accelerated recovery. Kaplan - Meier was used to estimate the median time required for recovery. Analysis is done using SPSS (IBM SPSS Statistics for Windows, Version 26.0, Armonk, NY: IBM Corp. Released 2019). Relative risk was calculated to assess the significance of difference in the event of COVID stage progression between the groups. Rate ratio was estimated in the overall recovery between groups. Significance level was fixed as $5 \%(a=0.05)$.

\section{Results}

Between 20 July 2020 and 4 December 2020, 383 patients were screened, of which 183 patients were excluded due to reasons such as not meeting the inclusion criteria of not willing to participate, renal complications, sepsis and Acute respiratory distress syndrome (ARDS). Two hundred (200) patients who were found eligible and volunteered to participate in the trial were recruited. One hundred (100) patients each were randomly assigned to each treatment and control group. Five patients in the control group discontinued participation in the study and all the 100 in treatment group participated through the trial. In the treatment group, 8 (8.0\%) mild, $12(12.0 \%)$ moderate and $80(80.0 \%)$ severe patients were enrolled while $12(12.0 \%)$ mild, 7 (7.0\%) moderate and 81 (81.0\%) severe patients in the control group (Figure 1).

\subsection{Demographic and baseline characteristics of study patients}

Descriptive statistics of baseline characteristics showed that they were evenly distributed between the two groups. Demographic characteristics, vital parameters, co-morbidities and the clinical signs and symptoms at baseline are presented in Table 2. The median age of study patients was 53 years in treatment group and 56 years in control group. There were $80(80.0 \%)$ males in the treatment group and $72(72.0 \%)$ in the control group. The number of patients in the age category of $46-64$ years in the treatment group was 49 (49.0\%) and $43(43.0 \%)$ in the control group. Those in the age category 18 to 29 years were less in both the treatment and control groups ( $n=7$ each group; 7.0\%). Diabetes was the most common co-morbidity in the treatment (48.0\%) and control groups (44.0\%), followed by hypertension in treatment $(23.0 \%)$ and in the control (36.0\%) groups. At the time of hospital admission, the mild and moderate COVID-19 patients predominantly presented with complaints of fever $(58.9 \%)$ and cough $(38.5 \%)$. But the severe category $(n=161)$ patients predominantly presented with complaints of difficulty in breathing (100.0\%) and fever (65.8\%). Symptoms such as difficulty in breathing, headache, loss of smell, myalgia, diarrhea, loss of taste, nausea, vomiting, sore throat, fatigue, chills or rigor and nasal congestion were also reported by the mild and moderate categories at the time of admission. 
Table 2

Personal and baseline characteristics of mild, moderate and severe COVID-19 study patients

\begin{tabular}{|c|c|c|}
\hline \multirow[t]{2}{*}{ Characteristics } & $\begin{array}{l}\text { Treatment group } \\
(n=100)\end{array}$ & $\begin{array}{l}\text { Control group } \\
(n=100)\end{array}$ \\
\hline & Mean \pm SD (or) $n(\%)$ & Mean \pm SD (or) $n(\%)$ \\
\hline Age [years (Median (Q1, Q3)] & $52.5(41.0,60.5)$ & $56.0(45.0,65.0)$ \\
\hline $18-29$ & $7(7.0)$ & $7(7.0)$ \\
\hline $30-45$ & $29(29.0)$ & $19(19.0)$ \\
\hline $46-64$ & $49(49.0)$ & $43(43.0)$ \\
\hline$\geq 65$ & $15(15.0)$ & $31(31.0)$ \\
\hline \multicolumn{3}{|l|}{ Gender } \\
\hline Male & $80(80.0)$ & $72(72.0)$ \\
\hline \multicolumn{3}{|l|}{ Ethnicity } \\
\hline Mixed & $100(100.0)$ & $100(100.0)$ \\
\hline \multicolumn{3}{|l|}{ Severity category } \\
\hline Mild & $8(8.0)$ & $12(12.0)$ \\
\hline Moderate & $12(12.0)$ & $7(7.0)$ \\
\hline Severe & $80(80.0)$ & $81(81.0)$ \\
\hline \multicolumn{3}{|l|}{ Vital parameters } \\
\hline $\mathrm{SpO}_{2}$ (Room air) & $85.8 \pm 7.2$ & $83.5 \pm 10.3$ \\
\hline Respiratory rate/minute & $35.0 \pm 10.9$ & $36.0 \pm 12.9$ \\
\hline Heart rate/minute & $93.4 \pm 14.0$ & $89.7 \pm 15.1$ \\
\hline Temp ( $\left.{ }^{\circ} \mathrm{F}\right)$ & $98.6 \pm 0.1$ & $98.9 \pm 3.3$ \\
\hline Systolic Blood pressure & $124.3 \pm 10.9$ & $124.0 \pm 13.1$ \\
\hline Diastolic Blood pressure & $77.4 \pm 5.6$ & $78.0 \pm 6.5$ \\
\hline $\mathrm{BMI}\left(\mathrm{kg} / \mathrm{m}^{2}\right)$ & $25.9 \pm 4.4$ & $25.6 \pm 3.8$ \\
\hline \multicolumn{3}{|l|}{ Presence of co-morbidity } \\
\hline 0 & $41(41.0)$ & $36(36.0)$ \\
\hline 1 & $41(41.0)$ & $37(37.0)$ \\
\hline$\geq 2$ & $18(18.0)$ & $27(27.0)$ \\
\hline \multicolumn{3}{|l|}{ Type of comorbidity } \\
\hline Diabetes & $48(48.0)$ & $44(44.0)$ \\
\hline
\end{tabular}

*One patient may present with more than one symptom

$\mathrm{SpO}_{2}-$ Oxygen Saturation of Peripheral circulation; BMI = Body Mass Index 


\begin{tabular}{|c|c|c|}
\hline \multirow[t]{2}{*}{ Characteristics } & $\begin{array}{l}\text { Treatment group } \\
(n=100)\end{array}$ & $\begin{array}{l}\text { Control group } \\
(n=100)\end{array}$ \\
\hline & Mean \pm SD (or) $n(\%)$ & Mean \pm SD (or) $n(\%)$ \\
\hline Hypertension & $23(23.0)$ & $36(36.0)$ \\
\hline Cardiovascular disease & $5(5.0)$ & $7(7.0)$ \\
\hline \multicolumn{3}{|l|}{ Clinical Symptoms * } \\
\hline At-least with one symptom & $98(98.0)$ & $92(92.0)$ \\
\hline Difficulty in breathing & $90(90.0)$ & $84(84.0)$ \\
\hline Fever & $67(67.0)$ & $64(64.0)$ \\
\hline Cough & $55(55.0)$ & $54(54.0)$ \\
\hline Myalgia & $15(15.0)$ & $12(12.0)$ \\
\hline Fatigue & $11(11.0)$ & $12(12.0)$ \\
\hline Diarrhoea & $11(11.0)$ & $4(4.0)$ \\
\hline Loss of smell & $9(9.0)$ & $7(7.0)$ \\
\hline Headache & $9(9.0)$ & $6(6.0)$ \\
\hline Loss of taste & $7(7.0)$ & $9(9.0)$ \\
\hline Nausea or vomiting & $5(5.0)$ & $6(6.0)$ \\
\hline Loss of appetite & $5(5.0)$ & $0(0.0)$ \\
\hline Sore throat & $4(4.0)$ & $4(4.0)$ \\
\hline \multicolumn{3}{|l|}{ MuLBSTA score } \\
\hline $0-5(0.47-2.17)$ & $30(30.0)$ & $41(41.0)$ \\
\hline $6-10(2.92-9.33)$ & $57(57.0)$ & $39(39.0)$ \\
\hline $11-15(12.27-32.36)$ & $13(13.0)$ & $20(20.0)$ \\
\hline $\begin{array}{l}\text { Median time from symptom onset to randomization (Median (Q1, } \\
\text { Q3)] }\end{array}$ & $7.0(5.0-11.5)$ & $7.0(4.5-10.5)$ \\
\hline \multicolumn{3}{|l|}{ Conditions at randomization } \\
\hline 2 & $4(4.0)$ & $4(4.0)$ \\
\hline 3 & $2(2.0)$ & $1(1.0)$ \\
\hline 4 & $10(10.0)$ & $8(8.0)$ \\
\hline 5 & $54(54.0)$ & $43(43.0)$ \\
\hline 6 & $30(30.0)$ & $39(39.0)$ \\
\hline \multicolumn{3}{|l|}{ *One patient may present with more than one symptom } \\
\hline $\mathrm{SpO}_{2}-$ Oxygen Saturation of Peripheral circulation; $\mathrm{BMI}=$ Body $\mathrm{N}$ & Index & \\
\hline
\end{tabular}

\subsection{Treatment outcome}


Fifty nine (59.0\%) from treatment group and twenty seven $(27.0 \%)$ from control group had accelerated recovery which was significantly $(p<0.001)$ different. Twenty eight $(28.0 \%)$ in the treatment group and thirty seven $(37.0 \%)$ in the control group had normal recovery (after 7 days) (Table 3). In the control group thirty five (35.0\%) patients had COVID stage progression (deterioration from mild, moderate and severe COVID categories) of which thirty three (33.0\%) died during intervention whereas in the treatment group thirteen (13.0\%) had stage progression in which all of them (13.0\%) died [37]. In the control, two patients died without undergoing stage progression due to sudden cardiac arrest and cerebrovascular accident whereas no death was observed in the treatment group without stage progression (Table 7). The number of deaths during treatment were higher in the control group [33 (33.0\%)] compared to the treatment group [13 $(13.0 \%)$ ]. Three patients in the control group had died during the 90 day follow up. No death was reported in treatment group during the follow up period. In severe treatment group $(n=80), 42(52.5 \%)$ had accelerated recovery and $12(15.0 \%)$ died; and in severe control $(\mathrm{n}=81), 18(22.2 \%)$ had accelerated recovery and $32(39.5 \%)$ had died during intervention (Supplementary table 4). Treatment with Siddha formulations resulted in 63\% reduction in the COVID-19 stage progression compared with control group (RR: $0.37 ; 95 \% \mathrm{Cl}: 0.21,0.66 ; \mathrm{p}<0.001$ ).

Table 3

Treatment outcome of mild, moderate and severe COVID-19 study patients

\begin{tabular}{|c|c|c|c|}
\hline Treatment Outcome & $\begin{array}{l}\text { Treatment group }(\mathrm{N}=100) \\
\mathrm{n}(\%)\end{array}$ & $\begin{array}{l}\text { Control group }(\mathrm{N}=100) \\
\mathrm{n}(\%)\end{array}$ & p-value \\
\hline Accelerated Recovery * & $59(59.0)$ & $27(27.0)$ & \multirow[t]{4}{*}{$<0.001^{\#}$} \\
\hline Normal Recovery & $28(28.0)$ & $37(37.0)$ & \\
\hline Death & $13(13.0)$ & $33(33.0)$ & \\
\hline No recovery & $0(0.0)$ & $3(3.0)$ & \\
\hline \multicolumn{4}{|c|}{ * Accelerated recovery implies the recovery $\leq 7$ days. Recovery is measured with WHO clinical progression scal } \\
\hline
\end{tabular}

Table 7

COVID-19 Stage progression (from baseline) in mild, moderate and severe patients

\begin{tabular}{|lccc|}
\hline Stage progression & Treatment & Control & p-value \\
\hline Yes & $13(13.0)$ & $35(35.0)$ & $<0.001$ \\
\cline { 1 - 3 } No & $87(87.0)$ & $65(65.0)$ & \\
\hline Chi-square test is used. $p<0.05$ is considered significant. \\
\hline
\end{tabular}

\subsection{Hematological, biochemical parameters, liver function, renal function and immune markers}

As the hematological and bio-chemical parameters could not be performed for all patients at the end point, the values for the available patients are presented (Supplementary table 1). There was no significant difference between treatment and control groups. The percentage difference of lab values of both pre and post interventions also was found to be insignificant in both groups, though prognostic markers such as ferritin, IL-6 and D-dimer were reduced post treatment in many patients. No adverse reactions were observed clinically in both the groups. The laboratory parameters of blood cell count, blood and urine biochemistry did not show any alarming increase or decrease in values.

\subsection{Day / Week wise cumulative recovery}


Outcome of treatment on each day in both the groups is shown in figure 2. The relief of any one symptom was begun to be observed from day 2 in both the groups. After two days, the cumulative recovery was found to be slightly higher in the treatment group when compared to the control group. In the control group, the event of death had occurred as early as the 2nd day of intervention, whereas in the treatment group, it was from 5th day of the intervention. There was a steep rise in cumulative recovery in the treatment group (62\%) till day 8 (Control $34.0 \%)$. In control group, 19 (19.0\%) patients had died till day 7 while 4 (4.0\%) in the treatment group. Until day 14, 28 (28.0\%) died in the control group while 10 $(10.0 \%)$ in the treatment group.

Weekly outcomes about recovery are given in figure 5 . Cumulative weekly recovery shows that treatment group has higher proportions of recovery till 28 days. On day seven, 59 (59.0\%) recovered in the treatment group and 27 (27.0\%) in control group. On day fourteen, the cumulative recovery of the treatment group is $77(77.0 \%)$ and $53(53.0 \%)$ in control. By day twenty one, 85 (85.0\%) recovered in the treatment group and 61 (61.0\%) in the control. At twenty eighth day, 87 $(87.0 \%)$ recovered in treatment and $63(63.0 \%)$ in control. In all those who had recovered $(n=151)$ during intervention, the maximum time taken was 28 days.

\subsection{Accelerated recovery between the groups with reference to selected baseline parameters}

Certain subgroups of treatment group showed statistically significant difference $(p<0.05)$ of increased proportion of accelerated recovery when compared with control using non parametric test. This is shown in Table 4. 
Table 4

Comparison of accelerated recovery of based on selected subgroup characteristics

\begin{tabular}{|c|c|c|c|}
\hline \multirow[t]{3}{*}{ Characteristics } & \multicolumn{2}{|c|}{ Accelerated Recovery } & \multirow[t]{3}{*}{ p-value } \\
\hline & Treatment group & Control group & \\
\hline & n (\%) & n (\%) & \\
\hline \multicolumn{4}{|l|}{ Gender } \\
\hline Male & $44(55.0)$ & $20(27.8)$ & 0.001 \\
\hline Female & $15(75.0)$ & $7(25.0)$ & 0.001 \\
\hline \multicolumn{4}{|l|}{ Age } \\
\hline $18-45$ & $23(63.9)$ & $9(34.6)$ & 0.023 \\
\hline $46-64$ & $26(53.1)$ & $13(30.2)$ & 0.027 \\
\hline$\geq 65$ & $10(66.7)$ & $5(16.1)$ & $0.001^{\star}$ \\
\hline \multicolumn{4}{|l|}{ BMI } \\
\hline$<25$ & 31 (68.9) & 15 (36.6) & 0.003 \\
\hline$\geq 25$ & 27 (51.9) & $12(22.6)$ & 0.002 \\
\hline \multicolumn{4}{|l|}{ Comorbidity } \\
\hline Present & 32 (54.2) & $14(21.9)$ & $<0.001$ \\
\hline Absent & 27 (65.9) & $13(36.1)$ & 0.009 \\
\hline \multicolumn{4}{|l|}{ MuLBSTA score } \\
\hline $0-5(0.47-2.17)$ & 19 (63.3) & $16(39.0)$ & 0.043 \\
\hline $6-10(2.92-9.33)$ & 33 (57.9) & $9(23.1)$ & 0.001 \\
\hline $11-15(12.27-32.36)$ & $7(53.8)$ & $2(10.0)$ & $0.013^{*}$ \\
\hline \multicolumn{4}{|l|}{ SpO2 (\%) } \\
\hline$<75$ & $3(37.5)$ & $1(6.7)$ & $0.103^{*}$ \\
\hline $75-85$ & $14(50.0)$ & $5(22.7)$ & $0.078 *$ \\
\hline $85-90$ & 24 (64.9) & $11(33.3)$ & 0.008 \\
\hline$>90$ & $18(66.7)$ & $10(40.0)$ & 0.054 \\
\hline \multicolumn{4}{|l|}{ Disease category } \\
\hline Mild & $6(75.0)$ & $5(41.7)$ & $0.197 *$ \\
\hline Moderate & $11(91.7)$ & $4(57.1)$ & $0.117^{\star}$ \\
\hline Severe & $42(52.5)$ & $18(22.2)$ & $<0.001$ \\
\hline
\end{tabular}




\subsection{Univariate binary logistic regression to calculate Odds of accelerated recovery by Treatment}

Univariate binary logistic regression was performed to identify the factors which were associated with accelerated recovery. The results showed that treatment group (OR: 3.89; 95\% Cl: 2.2, 7.1) was better than the control group; the age group of $18-45$ years (OR: 2.20; $95 \%$ Cl: $1.1,4.9)$ was compared with older age group ( $\geq 65$ years); BMI $(<25)$ was compared with $\mathrm{BMI} \geq 25$ (OR: 1.95; 95\% Cl: 1.1, 3.5); absence of co-morbidity (OR: 1.81; 95\% Cl: 1.0, 3.2) with presence of co-morbidity ; MuLBSTA score range 0 - 5 (OR: 2.59; 95\% Cl: 1.1, 6.4) and 6 - 10 (OR: 2.07; 95\% Cl: 0.9, 4.9) with 1115 and SpO2 levels 85 - 90\% (OR: 4.75; 95\% Cl: 1.5, 15.4) and >90\% (OR: 5.54; 95\% Cl: 1.7, 18.6) with SpO2 <75\% under room air. Thus the above subgroups were associated with accelerated recovery (Table 5). 
Table 5

Univariate Binary Logistic Regression to calculate Odds of accelerated recovery

\begin{tabular}{|c|c|c|c|c|}
\hline \multirow[t]{2}{*}{ Factors } & \multirow[t]{2}{*}{ Odds Ratio (Crude) } & \multicolumn{2}{|c|}{$95 \% \mathrm{Cl}$ for OR } & \multirow[t]{2}{*}{$\mathrm{p}$-value } \\
\hline & & LL & UL & \\
\hline \multicolumn{5}{|l|}{ Treatment } \\
\hline Control group & Ref & & & \\
\hline Treatment group & 3.891 & 2.147 & 7.052 & $<0.001$ \\
\hline \multicolumn{5}{|l|}{ Gender } \\
\hline Male & Ref & & & \\
\hline Female & 1.163 & 0.606 & 2.235 & 0.649 \\
\hline \multicolumn{5}{|l|}{ Age (years) } \\
\hline$\geq 65$ & Ref & & & \\
\hline $18-45$ & 2.204 & 1.100 & 4.870 & 0.050 \\
\hline $46-64$ & 1.521 & 0.724 & 3.195 & 0.268 \\
\hline \multicolumn{5}{|l|}{ BMI } \\
\hline$\geq 25$ & Ref & & & \\
\hline$<25$ & 1.946 & 1.090 & 3.475 & 0.024 \\
\hline \multicolumn{5}{|l|}{ Comorbidity } \\
\hline Present & Ref & & & \\
\hline Absent & 1.810 & 1.016 & 3.223 & 0.044 \\
\hline \multicolumn{5}{|c|}{ MuLBSTA score (mortality level) } \\
\hline $11-15(12.27-32.36)$ & Ref & & & \\
\hline $0-5(0.47-2.17)$ & 2.593 & 1.058 & 6.353 & 0.037 \\
\hline $6-10(2.92-9.33)$ & 2.074 & 0.873 & 4.930 & 0.099 \\
\hline \multicolumn{5}{|l|}{ SpO2 (\%) } \\
\hline$<75$ & Ref & & & \\
\hline $75-85$ & 2.911 & 0.859 & 9.862 & 0.086 \\
\hline $85-90$ & 4.750 & 1.466 & 15.391 & 0.009 \\
\hline$>90$ & 5.542 & 1.655 & 18.551 & 0.005 \\
\hline \multicolumn{5}{|l|}{ Disease category } \\
\hline Severe & Ref & & & \\
\hline Mild & 2.057 & 0.806 & 5.252 & 0.131 \\
\hline Moderate & 6.312 & 2.002 & 19.902 & 0.002 \\
\hline
\end{tabular}




\subsection{Multivariate binary logistic regression to calculate Odds of accelerated recovery by Treatment}

When we adjusted for every other factor such as gender, age, BMI, presence of comorbidity, MuLBSTA score, level of $\mathrm{SpO} 2$ and the severity category of disease the accelerated recovery for treatment group is nearly four times better than the control group (OR: 3.9; 95\% Cl: 1.9, 8.0; $<$ 0.001) which is statistically significant (Table 6).

Table 6

Multivariate Binary Logistic Regression to calculate Odds of accelerated recovery

\begin{tabular}{|c|c|c|c|c|c|c|c|c|}
\hline \multirow[t]{2}{*}{ Factors } & \multirow[t]{2}{*}{ Adj OR* } & \multicolumn{2}{|c|}{$95 \% \mathrm{Cl}$} & \multirow[t]{2}{*}{ p-value } & \multirow{2}{*}{ Adj OR\# } & \multicolumn{2}{|l|}{$95 \% \mathrm{Cl}$} & \multirow[t]{2}{*}{ p-value } \\
\hline & & LL & UL & & & LL & UL & \\
\hline $\begin{array}{l}\text { Treatment } \\
\text { (Treatment group) }\end{array}$ & & & & & 3.854 & 1.861 & 7.980 & $<0.001$ \\
\hline Gender & 4.024 & 2.204 & 7.349 & $<0.001$ & & & & \\
\hline Age (years) & 3.704 & 2.024 & 6.777 & $<0.001$ & & & & \\
\hline BMI level & 3.759 & 2.035 & 6.944 & $<0.001$ & & & & \\
\hline Comorbidity & 3.878 & 2.127 & 7.069 & $<0.001$ & & & & \\
\hline MuLBSTA score & 4.149 & 2.233 & 7.710 & $<0.001$ & & & & \\
\hline SpO2 (\%) & 3.606 & 1.945 & 6.683 & $<0.001$ & & & & \\
\hline Disease category & 4.104 & 2.197 & 7.667 & $<0.001$ & & & & \\
\hline
\end{tabular}

\subsection{Kaplan-Meier survival analysis for Recovery (Intervention) period, Disease days \& Hospital stay}

Kaplan-Meier survival analysis was performed to estimate median time for recovery, which is 7 days for treatment group with $95 \% \mathrm{Cl}: 6.0,8.0$. In the control group, the estimated median time for recovery is 10 days, $95 \% \mathrm{Cl}: 8.7,11.3$, which is statistically significant by Log Rank (Mantel-Cox) test $(p=0.003)$. The results are presented in Supplementary Table $2 \&$ Figure 3a

Kaplan-Meier survival analysis was performed to estimate median time for disease days, which is 16 days for treatment group with $95 \% \mathrm{Cl}$ : 13.8, 18.2 and in the control group, it is 17 days, $95 \% \mathrm{Cl}$ : 14.4, 19.6, which is statistically significant by Log Rank (Mantel-Cox) test $(p=0.036)$. The results are presented in Supplementary Table 2 \& Figure $3 b$

Kaplan-Meier survival analysis performed for hospital days estimated the median as 12 days in the treatment group with 95\% Cl: 10.7, 13.3 and in the control, it was 12 days, $95 \% \mathrm{Cl}: 10.6,13.4$, which is not statistically significant by Log Rank (Mantel-Cox) test $(\mathrm{p}=0.140)$. The results are presented in Supplementary Table 2 \& Figure 3c

\subsection{Cox proportional hazard model}

The Hazard rate of death in the control group is two and half times higher than that of treatment group (HR: 2.26; $95 \%$ Cl: $1.9,4.3 ; p=0.013$ ) (Supplementary table 3) \& (Figure 4). The proportion of death is higher in the gender male, age 
category $\geq 65$ years, BMI $\geq 25$, presence of co-morbidity, MuLBSTA score 11 - 15, SpO2 (\%) Room air (< 75) compared to other categories in both the groups (Supplementary table 4).

\subsection{Post-treatment follow up}

The outcome of the patients in terms of functionality, lingering breathlessness and quality of life followed through 30 day, 60-day and 90-days post recovery is depicted in Tables 8, 9 \&10 and supplementary tables 5, 6 \& 7.

Table 8

Post interventional assessment through Post COVID Functional Status Scale (PCFS) in patients

\begin{tabular}{|llll|}
\hline PCFS & $\begin{array}{l}\text { Treatment }(\mathbf{N}=\mathbf{9 5}) \\
\mathrm{n}(\%)\end{array}$ & $\begin{array}{l}\text { Control }(\mathrm{N}=89) \\
\mathrm{n}(\%)\end{array}$ & p-value \\
\hline 30th day & $49(51.6)$ & $24(27.0)$ & 0.001 \\
\hline 60 th day & $67(70.5)$ & $36(40.4)$ & 0.094 \\
\hline 90th day & $71(74.7)$ & $42(47.2)$ & 0.016 \\
\hline $\begin{array}{l}\text { Proportion of patients who had zero score in PCFS is furnished here; Chi-square test is used; } \mathrm{p}<0.05 \text { is considered } \\
\text { significant. }\end{array}$
\end{tabular}

\section{Table 9}

Assessment of lingering breathlessness post recovery in the patients

\begin{tabular}{|llll|}
\hline mMRC & $\begin{array}{l}\text { Treatment } \\
(\mathbf{N}=95)\end{array}$ & $\begin{array}{l}\text { Control } \\
(\mathbf{N}=89)\end{array}$ & p-value \\
& $\mathbf{n}(\%)$ & $\mathbf{n}(\%)$ & 0.053 \\
\hline 30 th day & $59(62.1)$ & $31(34.8)$ & 0.057 \\
\hline 60 th day & $67(70.5)$ & $34(38.2)$ & 0.016 \\
\hline 90th day & $71(74.7)$ & $41(46.1)$ & \\
\hline $\begin{array}{l}\text { Proportion of patients who had zero score in mMRC is furnished here; Chi-square test is used. } \mathrm{p}<0.05 \text { is considered } \\
\text { significant. }\end{array}$
\end{tabular}

Table 10

Quality of life assessment using EQ5D5L

\begin{tabular}{|c|c|c|c|c|c|}
\hline \multirow[t]{3}{*}{ EQ5D5L } & \multicolumn{2}{|c|}{ Treatment $\left(\mathrm{N}_{1}=95\right)^{\#}$} & \multicolumn{2}{|c|}{ Control $\left(\mathrm{N}_{2}=89\right)^{\#}$} & \multirow[t]{3}{*}{ p-value* } \\
\hline & EQ5D5L Index & $\mathrm{n}(\%)$ & EQ5D5L Index & n (\%) & \\
\hline & \multicolumn{2}{|l|}{$($ Mean \pm SD ) } & \multicolumn{2}{|l|}{$($ Mean \pm SD $)$} & \\
\hline 30th day & $0.91 \pm 0.2$ & $62(65.3)$ & $0.80 \pm 0.3$ & $28(31.5)$ & $<0.001$ \\
\hline 60th day & $0.93 \pm 0.2$ & 66 (69.5) & $0.82 \pm 0.3$ & $31(34.8)$ & 0.003 \\
\hline 90th day & $0.94 \pm 0.2$ & 68 (71.6) & $0.87 \pm 0.3$ & $39(43.8)$ & 0.076 \\
\hline \multicolumn{6}{|c|}{$\begin{array}{l}\text { Proportion of patients who had the score one in EQ5D } 5 \mathrm{~L} \text { is furnished here; *t test is used. } p<0.05 \text { is considered } \\
\text { significant. }\end{array}$} \\
\hline
\end{tabular}

\section{Discussion}


In the current study, we found that among the recruited of COVID-19 patients at the tertiary care hospital, the proportions of severe COVID-19 patients in both groups were higher than mild and moderate categories. The distribution of patients recruited in the study was markedly higher in the age group 46 - 64 years which corroborates with other studies reported on the age distribution of patients in COVID-19 all over the world during the first wave of the pandemic [38]. The average recovery period from COVID-19 is among the lowest (7 days) in the state of Tamil Nadu when compared to other and even neighboring Indian states [39]. During this pandemic in Tamil Nadu, mass distribution, door to door campaign and the household practice of taking the herbal concoctions Kabasura Kudineer and Nilavembu Kudineer might have a role in the facilitated recovery from COVID-19. This evinces interest in conducting studies to evaluate the possible association of consuming the concoctions and other Siddha medicines with shortened recovery time. Many randomized controlled clinical trials have been conducted in various parts of the world on COVID-19 and therapeutic interventions. Among the published trials some of them are related to the reduced time of recovery and thereby the reduced length of hospital stays and reduced mortality. The RECOVERY trial showed an absolute risk reduction in mortality by $2.8 \%$ with dexamethasone over control $[40,41]$. In our study, the risk reduction in mortality was by $20 \%$ (difference between treatment and control) with Siddha intervention. Treatment with Hydroxy-chloroquine (HCQ) and Lopinavir / Ritonavir did not show any mortality benefit in either the RECOVERY or World Health Organization (WHO) Solidarity trials [40]. The National Institutes of Health (NIH) and Brazilian HCQ trials did not show any benefit for HCQ based on the seven-point ordinal scale outcomes [42].

This study consisting of the Siddha regimen as an add-on intervention with Standard of Care was associated significantly with accelerated recovery as compared to only Standard of Care using logistic regression model. The accelerated recovery was 2.3 times higher in treatment than the control group in severe cases. The ACTT-1 trial involved recruitment of $(\mathrm{N}=1063)$ mild, moderate, severe and critical cases which showed that treatment with Remdesivir reduced the time to recovery by 4 days [43]. In this study the recovery time has been reduced by 3 days when compared to control. Beneficial effect was observed in the recovery days (median, 7 days, as compared with 10; rate ratio for recovery, 1.48 [ $95 \% \mathrm{Cl}, 1.06$ to 2.08]). Similarly, the COVID stage progression was effectively prevented in treatment group by the add-on Siddha treatment and it was $63 \%$ lower in treatment group than control. The difference in the median disease days between the groups is marginal, but significantly less in treatment group. Whereas no difference was observed in the length of hospital stay which is due to the hospital policy that was to manage and observe the severe COVID cases for minimum period of 10 days.

MuLBSTA score, which is a 90 days viral pneumonia predictor index for death in COVID-19 according to Guo et al., 2019 [44] was calculated in this study at baseline in severe category. It has predicted the average mortality as $8.2 \%$ and $6.8 \%$ (mode $=7.0 \%$ ) in treatment and control groups respectively. At the endpoint, the all-cause 90 day cumulative mortality in severe COVID category of treatment and control groups were $15 \%$ and $40.7 \%$ respectively. In severe cases, the proportion of death was 2.9 times less in treatment than the control which depicts the effectiveness of the Siddha intervention in reducing the mortality. The difference in proportion of death was significantly higher in the control group than treatment group which was derived using Cox proportional hazard model. In this study, 90-days post interventional follow up was carried out to assess the long term effectiveness of both the Siddha treatment and convalescence medications, we observed that there were 3 deaths in the control group and no death in treatment group. This also exhibited the long term effectiveness of Siddha intervention in the treatment group. The 90 day follow up assessment showed significant improvement in the overall functionality and quality of life and reduction of lingering breathlessness as compared to the Control group.

The safety of selected Siddha regimen was assessed by adverse drug reactions and basic blood parameters such as hematology, biochemistry, renal and liver function tests. It was observed that there were no adverse drug reactions or alarming increase or decrease in the investigatory values. Hence, the selected Siddha regimen can be considered to be 
safe as an add-on intervention to the standard care. Day-wise and weekly (7th, 14th, 21st \& 28th day) treatment outcome in terms of recovery was observed to be quicker in treatment than control group.

Few studies and a press release revealed that the traditional Chinese medicine was effective in the reduction of mortality of COVID-19 especially in the critically ill patients $[45,46]$. There are published protocols available in Ayurveda, Homeopathy and Unani for randomized clinical trials for COVID-19 [47, 48]. A randomized placebo controlled pilot clinical trial was conducted using an Ayurvedic treatment regimen on asymptomatic COVID-19 patients. It resulted in $100 \%$ recovery at day 7 in the trial group and reduction of the risk of viral dissemination [49]. As life threatening eventualities were possible in this study which recruited moderate and severe COVID-19 cases, a standalone placebo group could not be incorporated in the study design [23]. Another open clinical trial in mild and moderate COVID -19 was conducted using selected Siddha regimen which revealed that the effect of integrated approach for COVID-19 management was beneficial in terms of speedy recovery thereby reducing the hospitalization days [22]. The findings of our study also corroborate with the results of the above study.

As mortality is an outcome in this study, the selected Siddha interventions were given along with the standard care due to ethical considerations. Hence, the interference of the standard care may have played a role in the outcome. Since it is not a blinded clinical trial, to minimize the observer and assessment bias, dispensing of trial drugs to the study patients and the assessment of outcome parameters were done by the different individuals with assessment training from the study team. Since it was not feasible to perform the lab investigations for all the patients at endpoint we could not describe the specific hematological and immunological parameters associated with the accelerated recovery and prevention of mortality. Most of the participants were from South India, belonging to severe category of COVID-19 and were adult males. Therefore, the results of this study may be further validated with multicentric trials in other states of India.

To sum up, this first Siddha RCT to evaluate the effects of Siddha regimens on COVID-19 patients particularly in severe cases demonstrated that the Siddha medicines can help in the accelerated clinical recovery and reduce all-cause mortality. No adverse effect was observed to be associated with Siddha regimen. Selected Siddha decoctions, Churnam, Chenduram and Parpam dosage forms when co-administered with Standard of Care has demonstrated that they can synergistically relieve the respiratory distress and improve oxygenation status of patients as compared to administration of only Standard of Care.

\section{Recommendations}

This study is proof of concept that Siddha medicines when added to SOC can reduce recovery time and mortality, especially among severe COVID-19 patients. Double blind, placebo controlled, randomized multicentric clinical trials with Siddha regimen is recommended at national and international levels to generalize.

\section{Declarations}

\section{Ethics approval:}

Ethics approval was obtained from the Institutional Ethics Committee of Government Chengalpattu Medical College (Reg. No ECR/774/INST/TN/2015/RR-18). The trial was conducted in accordance with the principles of the Declaration of Helsinki [23] and the International Conference on Harmonization-Good Clinical Practice guidelines [24]. The study protocol was registered prospectively with Clinical Trial Registry of India (Trial registration number: CTRI/2020/06/025768).

\section{Declaration of competing interest}


The authors declare no conflict of interest with regards to the current work. This study was funded by SKM Siddha Ayurveda Company (India) Pvt. Ltd. It was involved in the providing of the study drugs. The manuscript was prepared by Dr G. J. Christian, Dr. E. Rajalakshmi and the steering committee members. SKM Siddha Ayurveda Company (India) Pvt. Ltd has not been permitted take the final decision on content in the manuscript; it is exclusively retained by the Principal and Co-PIs. Clinical trial was conducted by National Institute of Siddha, Tambaram, Chennai at Govt. Chengalpattu Medical College hospital, Chengalpattu district, Tamil Nadu, India.

\section{Author contributions:}

Christian Gnanaraj Johnson: Conceptualization, Methodology, Writing - Original Draft, Writing - Review \& Editing, Investigation, Supervision, Visualization

Meenakumari Ramasamy: Conceptualization, Methodology, Supervision, Visualization

Shanthimalar R: Conceptualization, Investigation

Sankar Ganesan: Supervision

Ravichandran Vadugam Muthusamy : Funding acquisition, Resources

Elansekaran Selladurai: Investigation

Ramamurthy Murugan: Investigation

Srinivasan Venkatachalam: Investigation

Rajalakshmi Elumalai: Software, Validation, Formal analysis, Writing - Original Draft, Writing - Review \& editing

Boopathi Kangusamy: Software, Validation, Formal analysis

Vennila Kesavan: Investigation

Nijavizhi Mohanasundaram: Investigation

Shakthi Paargavi Ambalavanan: Investigation

Aruldevi S: Investigation

Priyanka Sekaran: Investigation

Gajalakshmi G: Investigation

\section{Funding}

The study was sponsored by SKM Siddha and Ayurvedha Company (India) Private Limited, Erode, Tamil Nadu and Ministry of AYUSH, Government of India, New Delhi.

\section{Acknowledgements}

The collaboration was provided by the Govt. Chengalpattu Medical College (CMC), supported and patronized by the District administration, Chengalpattu. Our special thanks worth to Former District Collector, Chengalpattu Mr. John Louis and the Former Dean, Prof. Dr.R.Shanthimalar, CMC and Dr. G. Sankar, Director, Ezhil Siddha Hospital, Chengalpattu for their unstinted support. We place on record the gratitude to Dr. Manoj Murhekar, Director, ICMR - NIE for offering 
technical collaboration in the study design, conduct, analysis and publication. We thank SKM Siddha Ayurveda Company (India) Pvt. Ltd., IMPCOPS, Chennai and Earth India Naturals pharmaceuticals for providing the study drugs. We thank Ms. K. Poornima, Data Asst NIS for statistical assistance. We also thank members of the Scientific Advisory Committee, National Institute of Siddha, all the Teaching and Admin staff and Post Graduate students of National Institute of Siddha for the ministerial work and the clinical service rendered at COVID wards. We thank Medall Healthcare Pvt. Ltd (MEDALL) for their support in doing the various laboratory investigations and SARS-CoV-2 assay detection. The entire work is technically supported by the members and mentor of the Project Monitoring Unit of Ministry of AYUSH, Govt. of India. We profusely thank Prof. Dr. Padma Venkat, Dean, School of Public Health, SRMIST, Kattankulathur for mentoring this study as Ministry of AYUSH expert.

\section{References}

1. World Health Organisation, 2021. WHO Coronavirus (COVID-19) Dashboard, 2021. https://covid19.who.int (accessed 31.05.21).

2. World Health Organisation, 2021. India: WHO Coronavirus Disease (COVID-19) Dashboard With Vaccination Data, 2021. https://covid19.who.int (accessed 31.05.21).

3. Clinical Spectrum, 2021. COVID-19 Treatment Guidelines. https://www.covid19treatmentguidelines.nih.gov/overview/clinical-spectrum (accessed 03.06.2020).

4. Verity, R., Okell, L.C., Dorigatti, I., Winskill, P., Whittaker, C., Imai, N., Cuomo-Dannenburg, G., Thompson, H., Walker, P.G., Fu, H. and Dighe, A., 2020. Estimates of the severity of coronavirus disease 2019: a model-based analysis. The Lancet infectious diseases, 20, 669-677.

5. Li, X., Li, T. and Wang, H., 2020. Treatment and prognosis of COVID-19: Current scenario and prospects. Experimental and Therapeutic Medicine, 20, 1-1.

6. Tang, N., Li, D., Wang, X. and Sun, Z., 2020. Abnormal coagulation parameters are associated with poor prognosis in patients with novel coronavirus pneumonia. Journal of thrombosis and haemostasis, 18, 844-847.

7. Ge, H., Wang, X., Yuan, X., Xiao, G., Wang, C., Deng, T., Yuan, Q. and Xiao, X., 2020. The epidemiology and clinical information about COVID-19. European Journal of Clinical Microbiology \& Infectious Diseases, 39, 1011-1019.

8. Oliveira, E., Parikh, A., Lopez-Ruiz, A., Carrilo, M., Goldberg, J., Cearras, M., Fernainy, K., Andersen, S., Mercado, L., Guan, J., Zafar, H., Louzon, P., Carr, A., Baloch, N., Pratley, R., Silverstry, S., Hsu, V., Sniffen, J., Herrera, V., \& Finkler, N. (2021). ICU outcomes and survival in patients with severe COVID-19 in the largest health care system in central Florida. PloS one, 16(3), e0249038. https://doi.org/10.1371/journal.pone.0249038

9. Guan, W.J., Ni, Z.Y., Hu, Y., Liang, W.H., Ou, C.Q., He, J.X., Liu, L., Shan, H., Lei, C.L., Hui, D.S. and Du, B., 2020. Clinical characteristics of coronavirus disease 2019 in China. New England journal of medicine, 382, 1708-1720.

10. Centers for Disease Control and Prevention, 2020. CDC.COVID-19 and Your Health. https://www.cdc.gov/coronavirus/2019-ncov/need-extra-precautions/people-with-medical-conditions.html (accessed 03.06.2020)

11. Ministry of Health and Family Welfare, 2020. Updated Detailed Clinical Management Protocol for COVID19 adults dated 24.05.2021.

https://www.mohfw.gov.in/pdf/UpdatedDetailedClinicalManagementProtocolforCOVID19adultsdated24052021.pdf. (accessed 03.06.21)

12. Ministry of AYUSH, 2021. Guidelines for AYUSH practitioners for COVID-19. https://www.AYUSH.gov.in/AYUSHguidelines.html (accessed 01.06.21).

13. Ministry of AYUSH, 2021. Siddha-guidelines, 2021. https://www.AYUSH.gov.in/docs/siddha-guidelines.pdf (accessed 03.06.21).

Page $21 / 28$ 
14. Anbarasu, K., 2013. Yugi Vaithiya Chindhamani - 800, Moolamum uraiyum, Thamarai Noolagam, Tamil Nadu.

15. Thiyagarajan, R., Vaidhyachinthamani, Y., 1976. Perunool 800. Palani Thandayuthapani Devasthanam publications, Directorate of Indian systems of Medicine, Tamil Nadu.

16. Vincent, S., Arokiyaraj, S., Saravanan, M. and Dhanraj, M., 2020. Molecular docking studies on the anti-viral effects of compounds from Kabasura Kudineer on SARS-CoV-2 3CLpro. Frontiers in molecular biosciences, 7, 434.

17. Gangarapu, K., KM, K. and MS, S., 2020. In Silico Computational Screening of Kabasura Kudineer-Official Siddha Formulation and JACOM-Novel Herbal Coded Formulation Against SARS-CoV-2 Spike protein. Journal of Ayurveda and Integrative Medicine. 2020 May 25; S0975-9476(20)30024-3. doi: 10.1016/j.jaim.2020.05.009.

18. Prakash, P., Meena, R., Abraham, L.S., Sunkar S., Govindaraju, K., Pully, D and Samrot, A.V., 2021. Evidence-based traditional Siddha formulations for prophylaxis and management of respiratory symptoms in COVID-19 pandemic-a review. Biocatalysis and Agricultural Biotechnology, 102056.

19. Girija, P.L.T. and Sivan, N., 2020. Ayurvedic treatment of COVID-19/SARS-CoV-2: A case report. Journal of Ayurveda and Integrative Medicine.

20. Sangeetha, K., 2008. A study on in vitro antiviral activities of lyophilised extracts of medicinal plants alpinia galanga willd alpinia officinarum hance decalepis hamiltonii wight and arn vitex negundo linn tectona grandis linn hyptis suaveolens poit and of isolated compounds from tectona grandis linn to asian and african clades of chikungunya virus. University of Madras. http://shodhganga.inflibnet.ac.in:8080/jspui/handle/10603/193469

21. Christian, G.J., Meenakumari, R., Rajamaheswari, K., Priyanka Sekaran, Gajalakshmi, G., and Anand, T., 2021. "Phytochemical Screening of Adathodai Kudineer A Siddha Herbal Concoction and Evaluation of Its Binding Affinity With SARS-CoV-2 Spike Protein and ACE2 Receptor Spike Protein Complex through Molecular Docking in Silico Approach". International Journal of Ayurvedic Medicine 12, 366-74. https://doi.org/10.47552/ijam.v12i3.1762.

22. Chitra, S.M., Mallika, P., Anbu, N., NarayanaBabu, R., SugunaBai, A., Raj, R.D.P. and Premnath, D., 2021. An Open Clinical Evaluation Of Selected Siddha Regimen In Expediting The Management Of Covid-19-A Randomized Controlled Study. Journal of Ayurveda and Integrative Medicine.

23. WMA Declaration of Helsinki - ethical principles for medical research involving human subjects, 2018. World Medical Association. https://www.wma.net/policies-post/wma-declaration-of-helsinki-ethical-principles-for-medicalresearch-involving-human-subjects

24. ICH-E6 Good Clinical Practice (GCP), 2021. ICH: Harmonisation for better health. https://www.ich.org

25. State Licensing Authority of Indian Medicine, 2021. Rules \& Regulations. https://www.tnslaim.tn.gov.in/rules.html (accessed 04.06.21).

26. Ministry of AYUSH, 2021. Drugs and Cosmetics Rules, 1945 dated 02.07.2021. https://cdn.AYUSH.gov.in/wpcontent/uploads/2021/07/228177.pdf (accessed 04.06.21).

27. WHO Working Group on the Clinical Characterisation and Management of COVID-19 infection (2020). A minimal common outcome measure set for COVID-19 clinical research. The Lancet. Infectious diseases, 20, e192-e197. https://doi.org/10.1016/S1473-3099, 30483-7

28. Ministry of Health and Family Welfare, 2020. Discharge Policy of nCoV Case.

https://www.mohfw.gov.in/pdf/Corona\%20Discharge-Policy.pdf (accessed 26.06.2020)

29. Dr. K.N. Kuppusamy and Dr. K.S.Utthmarayan, H.P.I.M, 1998. Siddha Vaidhiya Thirattu -Amukkara Churanam: Directorate of Indian Medicine, Tamil Nadu, 213.

30. Indian Medicine and Homeopathy, 2020. "AAROKYAM" Special Programme with AYUSH Interventions for COVID-19 Implementation. Tamil Nadu.

31. Klok, F. A., Boon, G., Barco, S., Endres, M., Geelhoed, J., Knauss, S., Rezek, S. A., Spruit, M. A., Vehreschild, J., \& Siegerink, B., 2020. The Post-COVID-19 Functional Status scale: a tool to measure functional status over time after

Page 22/28 
COVID-19. The European respiratory journal, 56(1), 2001494. https://doi.org/10.1183/13993003.01494-2020

32. Stenton, C., 2008. The MRC breathlessness scale. Occupational Medicine, 58(3), pp.226-227.

33. EQ-5D -5L, 2020. https://euroqol.org

34. Repišti, S.,Jovanović, N.,Kuzman, M.,Medved, S.,Jerotić, S.,Ribić, E.,Majstorović, T.,Simoska, S.,Novotni, L.,Milutinović, M.,Stoilkovska, B.,Radojičić, T.,Ristić, I.,Zebić, M.,Pemovska, T. and Russo, M. 2020 How to measure the impact of the COVID-19 pandemic on quality of life: COV19-QoL - the development, reliability and validity of a new scale. Global Psychiatry, Vol.0 (Issue 0), pp. -. https://doi.org/10.2478/gp-2020-0016

35. Santus, P., Tursi, F., Croce, G., Di Simone, C., Frassanito, F., Gaboardi, P., Airoldi, A., Pecis, M., Negretto, G., \& Radovanovic, D, 2020. Changes in quality of life and dyspnoea after hospitalization in COVID-19 patients discharged at home. Multidisciplinary respiratory medicine, 15(1), 713. https://doi.org/10.4081/mrm.2020.713

36. Herdman, M., Gudex, C., Lloyd, A., Janssen, M.F., Kind, P., Parkin, D., Bonsel, G. and Badia, X., 2011. Development and preliminary testing of the new five-level version of EQ-5D (EQ-5D-5L). Quality of life research, 20(10), pp.1727-1736.

37. Gupta, A., Gonzalez-Rojas, Y., Juarez, E., Casal, M.C., Moya, J., Falci, D.R., Sarkis, E., Solis, J., Zheng, H., Scott, N. and Cathcart, A.L., 2021. Early Covid-19 Treatment With SARS-CoV-2 Neutralizing Antibody Sotrovimab. medRxiv.

38. Laxminarayan, R., Vinay, T.G., Kumar, K.A., Wahl, B. and Lewnard, J.A., 2021. SARS-CoV-2 infection and mortality during the first epidemic wave in Madurai, south India: a prospective, active surveillance study. The Lancet Infectious Diseases.

39. George, N., Tyagi, N.K. and Prasad, J.B., 2021. COVID-19 pandemic and its average recovery time in Indian states. Clinical Epidemiology and Global Health, 11, 100740.

40. Recovery Collaborative Group, Horby, P., Lim, W.S., Emberson, J.R., Mafham, M., Bel, J.L., Linsell, L., Staplin N, Brightling C, Ustianowski A, Elmahi E, Prudon B, Green C, Felton T, Chadwick D, Rege K, Fegan C, Chappell LC, Faust SN, Jaki T, Jeffery K, Montgomery A, Rowan K, Juszczak E, Baillie JK, Haynes R, Landray MJ.. Dexamethasone in Hospitalized Patients with Covid-19. N Engl J Med. 2021 Feb 25;384, 693-704.

41. Wang, Y., Zhang, D., Du, G., Du, R., Zhao, J., Jin, Y., Fu, S., Gao, L., Cheng, Z., Lu, Q. and Hu, Y., 2020. Remdesivir in adults with severe COVID-19: a randomised, double-blind, placebo-controlled, multicentre trial. The lancet, 395, 1569-1578.

42. Sterne, J.A., Murthy, S., Diaz, J.V., Slutsky, A.S., Villar, J., Angus, D.C., Annane, D., Azevedo, L.C.P., Berwanger, O., Cavalcanti, A.B. and Dequin, P.F., 2020. Association between administration of systemic corticosteroids and mortality among critically ill patients with COVID-19: a meta-analysis. Jama, 324, 1330-1341.

43. Beigel, J.H., Tomashek, K.M., Dodd, L.E., Mehta, A.K., Zingman, B.S., Kalil, A.C., Hohmann, E., Chu, H.Y., Luetkemeyer, A., Kline, S. and Lopez de Castilla, D., 2020. Remdesivir for the treatment of Covid-19. New England Journal of Medicine, 383, 1813-1826.

44. Guo L, Wei D, Zhang X, Wu Y, Li Q, Zhou M, et al. 2019. Clinical features predicting mortality risk in patients with viral pneumonia: the MuLBSTA score. Front Microbiology 10, 2752. https://doi.org/10.3389/fmicb.2019.02752.

45. Xinhuanet, 2021. TCM can help halve COVID-19 death rate: report. http://www.xinhuanet.com/english/202105/10/C_139935926.html (accessed on 14.07.21)

46. Sun, Q.G., An, X.D., Xie, P., Jiang, B., Tian, J.X., Yang, Q., Li, X.Y., Luo, M., Liu, P., Zhao, S.H. and Duan, L.Y., 2021. Traditional Chinese Medicine Decoctions Significantly Reduce the Mortality in Severe and Critically III Patients with COVID-19: A Retrospective Cohort Study. The American Journal of Chinese Medicine, 1-30.

47. Natarajan, S., Anbarasi, C., Sathiyarajeswaran, P., Manickam, P., Geetha, S., Kathiravan, R., Prathiba, P., Pitchiahkumar, M., Parthiban, P., Kanakavalli, K. and Balaji, P., 2020. The efficacy of Siddha Medicine, Kabasura Kudineer (KSK) compared to Vitamin C \& Zinc (CZ) supplementation in the management of asymptomatic COVID-19 cases: A structured summary of a study protocol for a randomised controlled trial. Trials, 21, 1-2.

Page 23/28 
48. Srivastava, A., Rengaraju, M., Srivastava, S., Narayan, V., Gupta, V. and Upadhayay, R., 2021. A double blinded placebo controlled comparative clinical trial to evaluate the effectiveness of Siddha medicines, Kaba Sura Kudineer (KSK) \& Nilavembu Kudineer (NVK) along with standard Allopathy treatment in the management of symptomatic COVID-19 patients-a structured summary of a study protocol for a randomized controlled trial. Trials, 22, 1-3.

49. Devpura, G., Tomar, B.S., Nathiya, D., Sharma, A., Bhandari, D., Haldar, S., Balkrishna, A. and Varshney, A., 2021. Randomized placebo-controlled pilot clinical trial on the efficacy of ayurvedic treatment regime on COVID-19 positive patients. Phytomedicine, 84, 153494.

50. Dr. K.N. Kuppusamy and Dr. K.S.Utthmarayan, H.P.I.M, 1998. Siddha Vaidhiya Thirattu -Kabasura Kudineer: Directorate of Indian Medicine, Tamil Nadu, 293.

51. Dr. K.N. Kuppusamy and Dr. K.S.Utthmarayan, H.P.I.M, 1998. Siddha Vaidhiya Thirattu -Nilavembu Kudineer: Directorate of Indian Medicine, Tamil Nadu, 294.

52. Dr. K.N. Kuppusamy and Dr. K.S.Utthmarayan, H.P.I.M, 1998. Siddha Vaidhiya Thirattu - Thalisathi Churanam: Directorate of Indian Medicine, Tamil Nadu, 225.

53. Dr. K.N. Kuppusamy and Dr. K.S.Utthmarayan, H.P.I.M, 1998. Siddha Vaidhiya Thirattu -Adathodai Manapagu: Directorate of Indian Medicine, Tamil Nadu, 259.

54. Dr. K.N. Kuppusamy and Dr. K.S.Utthmarayan, H.P.I.M, 1998. Siddha Vaidhiya Thirattu - Karuppu Vishnu Chakram Maathirai: Directorate of Indian Medicine, Tamil Nadu, 44.

55. Dr. K.N. Kuppusamy and Dr. K.S.Utthmarayan, H.P.I.M, 1998. Siddha Vaidhiya Thirattu -Adathodai Kudinner: Directorate of Indian Medicine, Tamil Nadu, 294.

56. Dr. K.N. Kuppusamy and Dr. K.S.Utthmarayan, H.P.I.M, 1998. Siddha Vaidhiya Thirattu - Nochi Kudineer: Directorate of Indian Medicine, Tamil Nadu, 294.

57. Dr. K.N. Kuppusamy and Dr. K.S.Utthmarayan, H.P.I.M, 1998. Siddha Vaidhiya Thirattu -Pavala Parpam: Directorate of Indian Medicine, Tamil Nadu, 121.

58. Dr. K.N. Kuppusamy and Dr. K.S.Utthmarayan, H.P.I.M, 1998. Siddha Vaidhiya Thirattu -Thippili Rasayanam: Directorate of Indian Medicine, Tamil Nadu, 235.

\section{Supplemental Data}

Supplementary Tables are not available with this version.

\section{Figures}




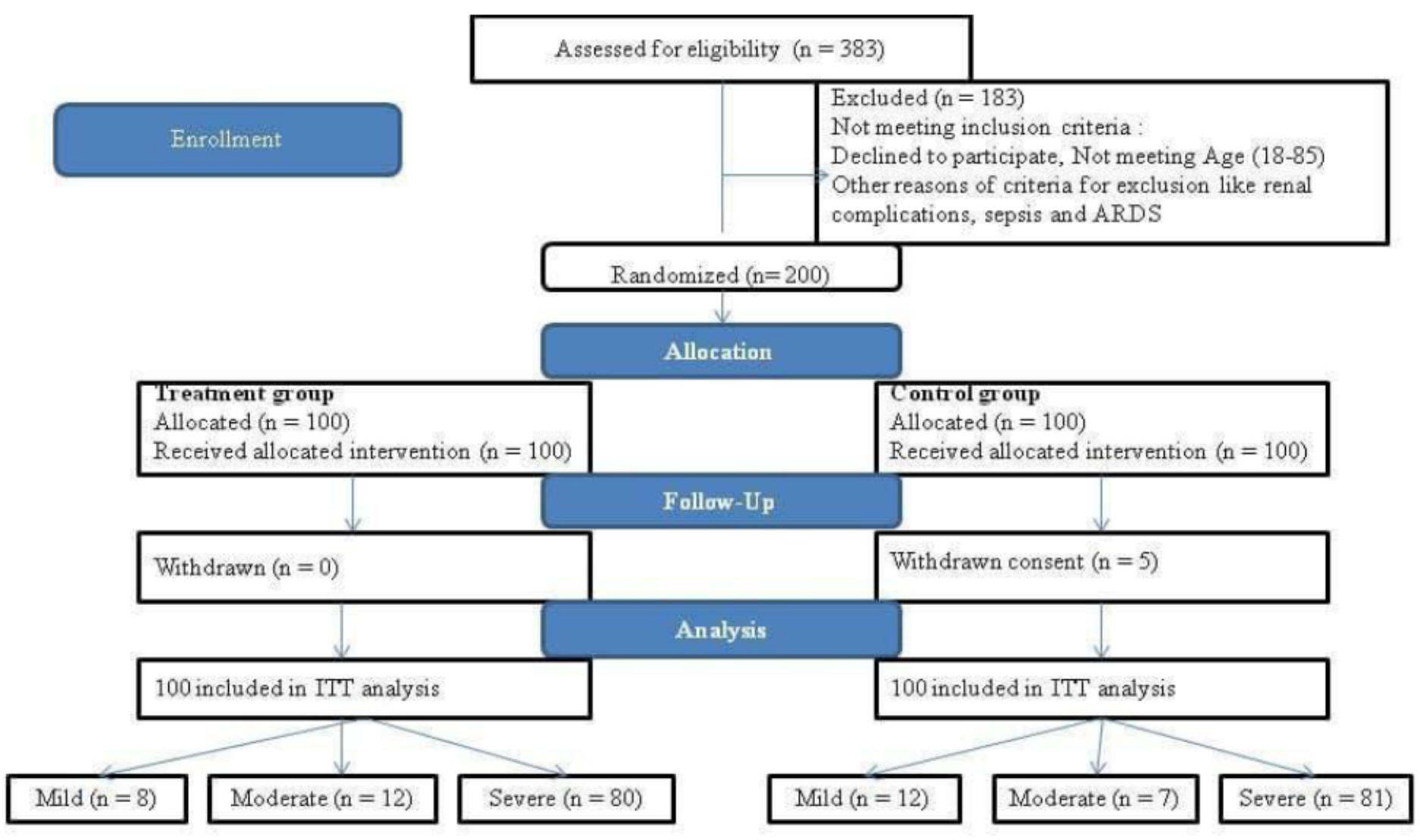

Figure 1

Trial Profile 


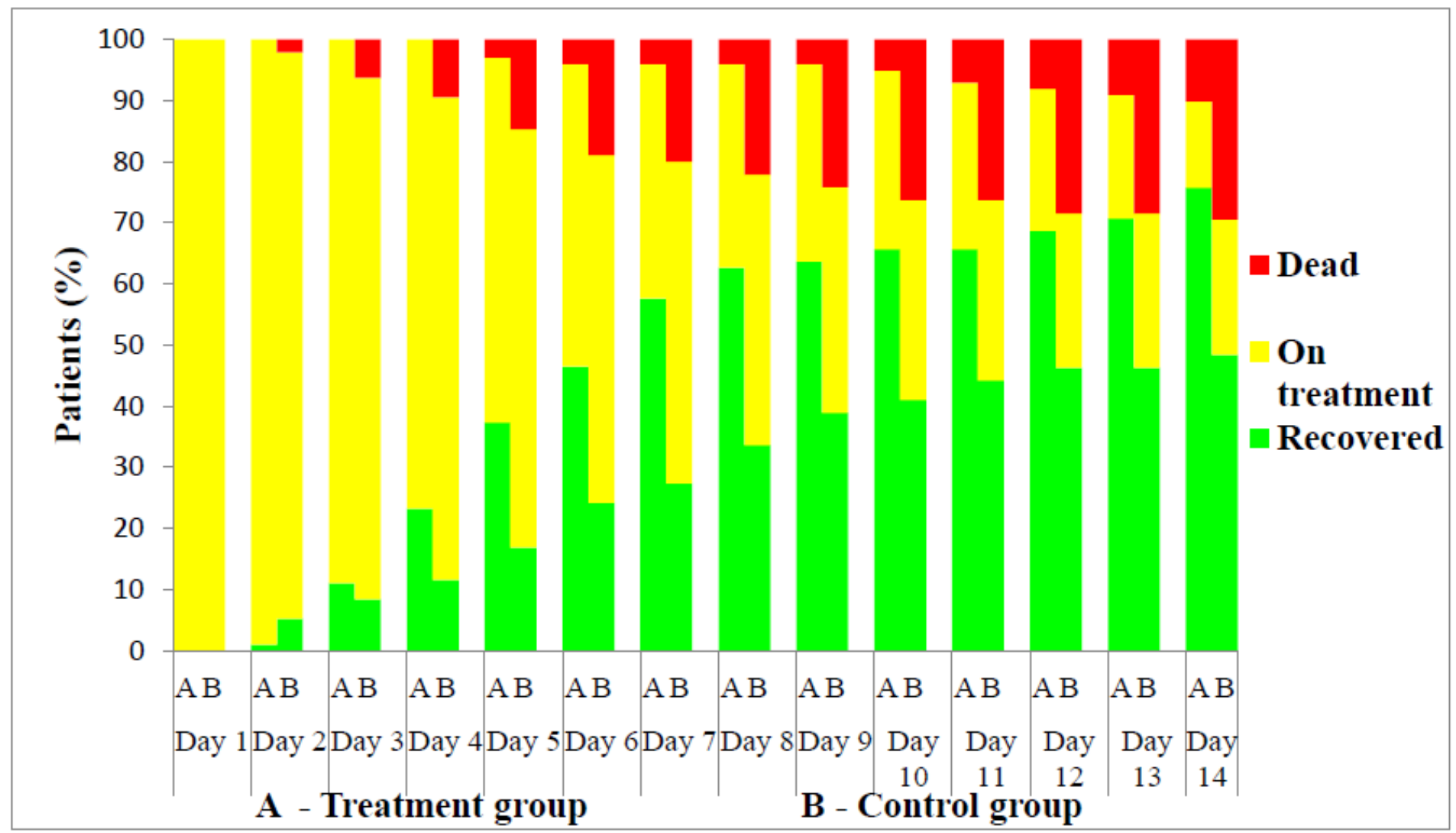

Figure 2

Treatment outcome of mild, moderate and severe COVID-19 study patients
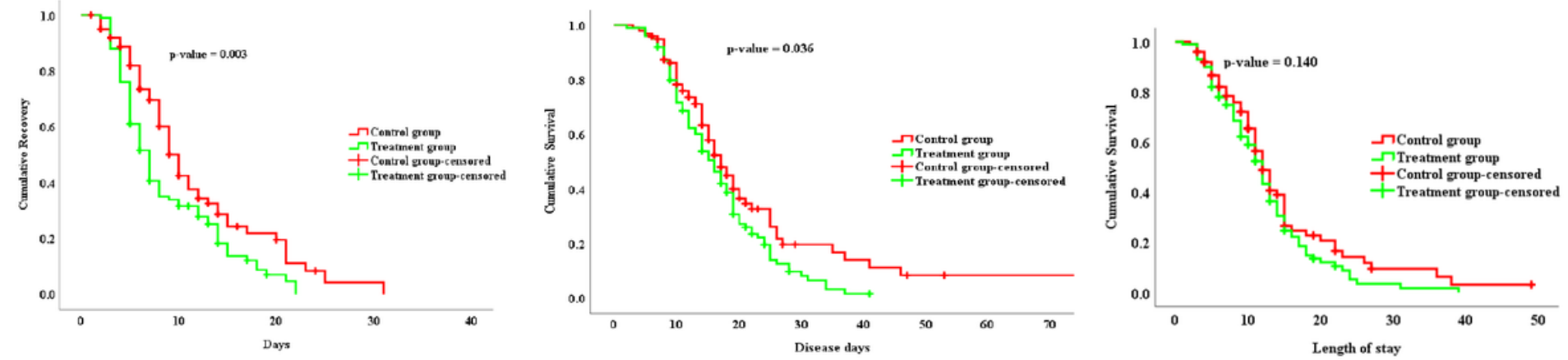

Figure 3

a: Kaplan-Meier survival plot for recovery (Intervention) period

b: Kaplan-Meier survival plot for Disease days

c: Kaplan-Meier survival plot for Hospital stay 


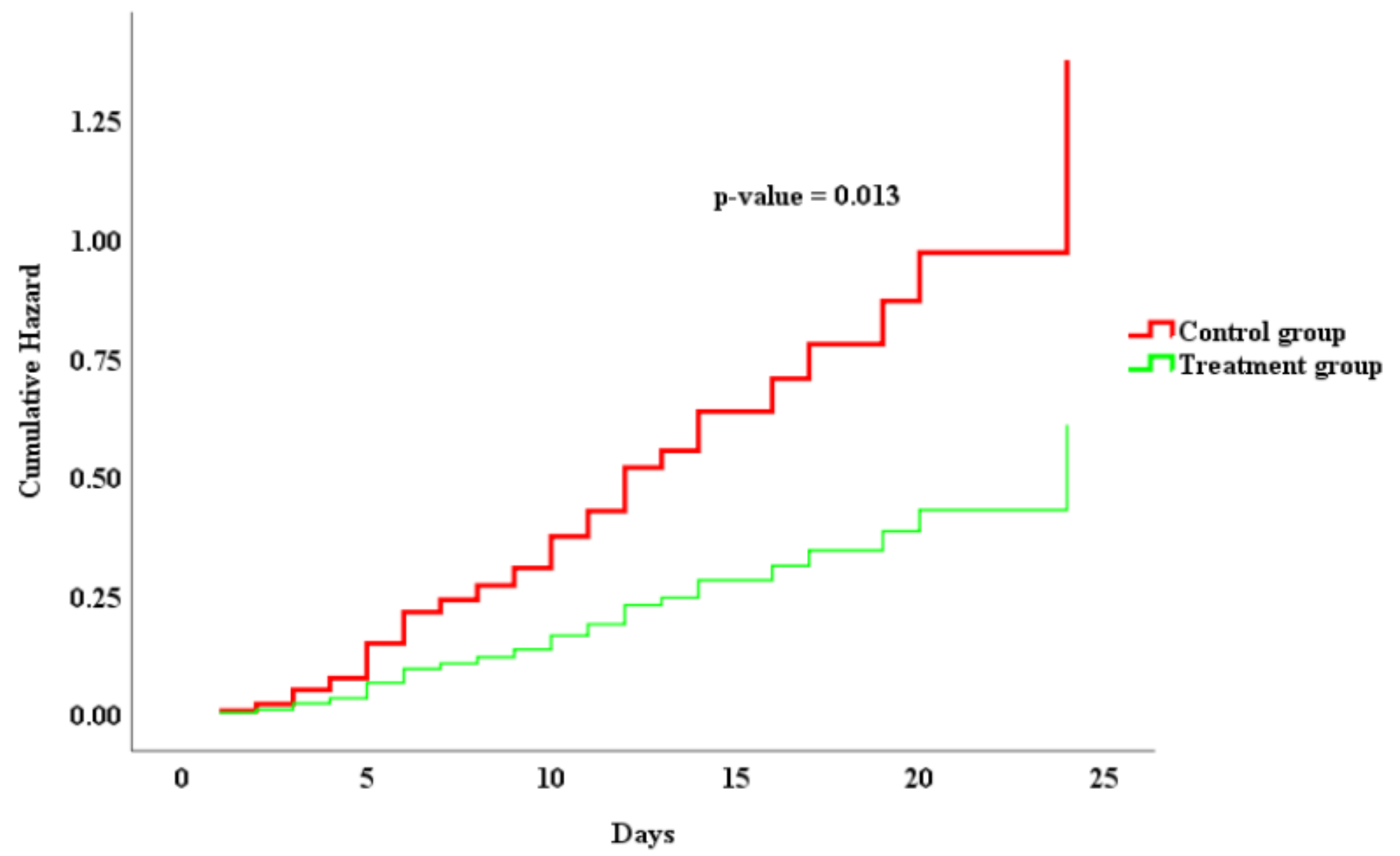

Figure 4

Hazard curve for death between treatment and control groups 


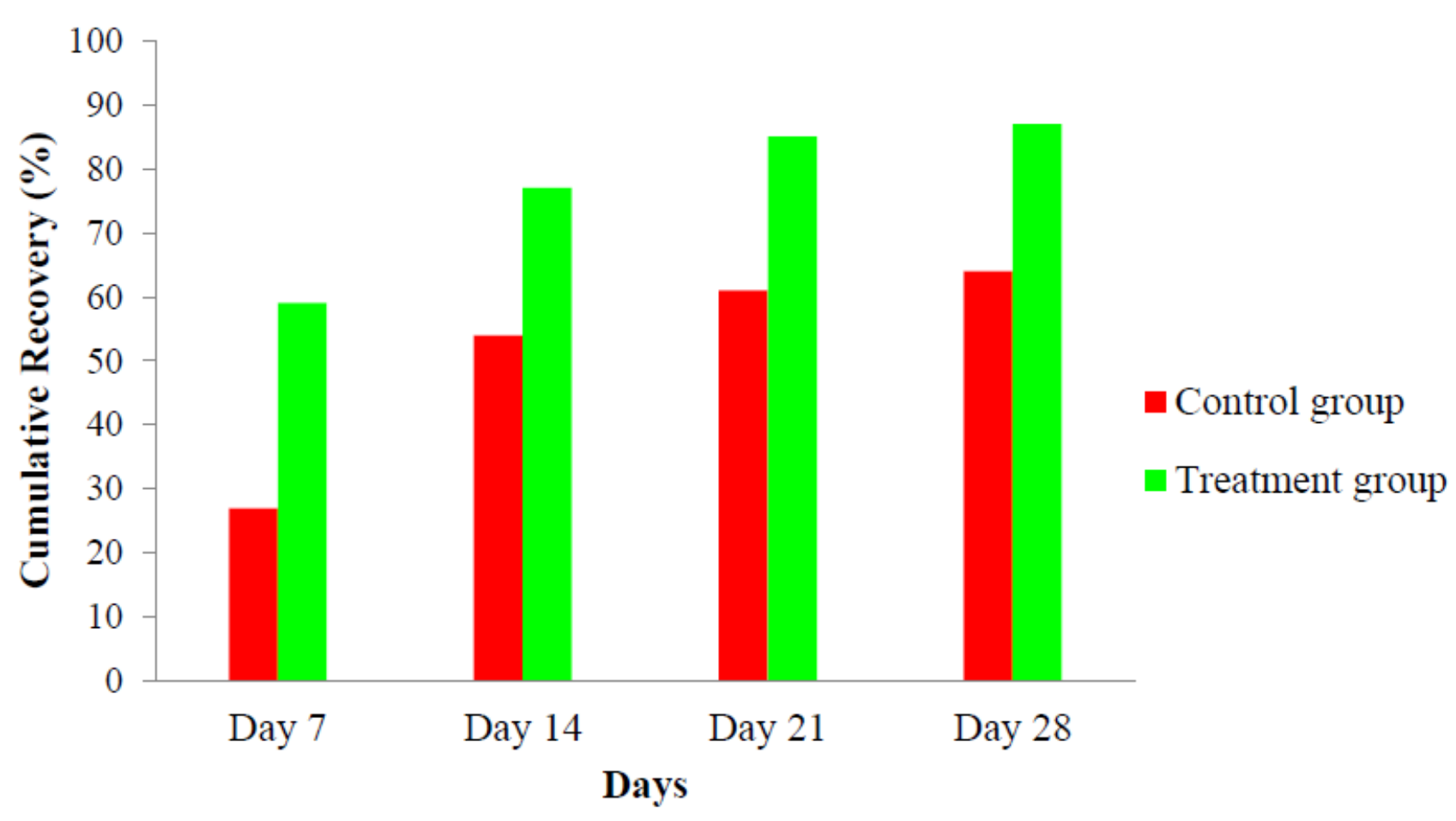

Figure 5

Cumulative recovery of mild, moderate and severe COVID-19 patients at different time points

\section{Supplementary Files}

This is a list of supplementary files associated with this preprint. Click to download.

- GraphicalAbstract.png

- CONSORT2010ChecklistMSWord.doc 